\title{
Auroral-Zone Pearl Pulsations ${ }^{1}$
}

\author{
R. L. McPherRon AND S. H. WARD \\ Space Sciences Laboratory, University of California, Berkeley
}

\begin{abstract}
An analysis has been made of Pc 1 band micropulsations observed in the auroral zone during one solar rotation at Flin Flon, Manitoba, August-September 1964. The Pc 1 band micropulsations were subdivided into pearl pulsations (PP), impulsive activity (IMP), and short irregular pulsations (SIP); this paper is concerned primarily with PP. We have observed: (1) there is no correlation of PP with electron precipitation indicated by bremsstrahlung recorded at balloon altitude; (2) PP type activity occurs at the time of a sudden commencement and can have an hourly repetition of occurrence for 5 or 6 hours thereafter; (3) the $K_{p}$ and $A_{p}$ indices are too coarse for adequate representation of geomagnetically disturbed times when studying the dependence of PP occurrence on geomagnetic activity; (4) there may be a slight increase of PP period with increase in K; (5) PP have higher amplitudes when $K$ values are higher; (6) Pc 3, 4 band activity may be used as a good predictor for PP occurrence, since, for days rated as disturbed by Pc 3,4 activity, there is an inverse correlation between PP and Pc 3, 4. For days rated as quiet by Pc 3, 4 activity, PP may occur at any time during the daylight hours; (7) PP are distributed throughout the daylight hours on quiet days, whereas they tend to appear only within an hour or two of $1800 \mathrm{LMT}$ on disturbed days. We can interpret these observations in terms of a hydromagnetic wave packet origin for PP with the occurrence of PP dependent on (1) triggering mechanism; (2) amplification mechanism; (3) guiding along field lines; (4) transmission through the ionosphere.
\end{abstract}

\section{INTRODUCTION}

During the period August 16 to September 20, 1964, we continuously recorded magnetic micropulsations at Flin Flon, Manitoba, geomagnetic coordinates $\left(63.6^{\circ} \mathrm{N}, 314.8^{\circ}\right)$. The purpose of these recordings was to obtain information on the characteristics of micropulsations at these latitudes and to examine the possibility of a relationship of micropulsations to electron precipitation. Simultaneous information on electrons was obtained from a number of high-altitude balloon flights carrying X-ray detectors.

\section{Experimental APPARATUS AND Data Reduction}

A schematic diagram of the magnetic micropulsation system used is shown in Figure 1. The currents induced in large induction coils were amplified, filtered, and recorded on strip chart recorders at speeds of 1 or 4 inches per minute. Typical Pc 1 band filter characteristics are shown in Figure 2.

Data reduction was done in two parts. The records were first logged in 10-minute intervals with respect to the occurrence, amplitude, and

\footnotetext{
${ }^{1}$ A contribution to the IQSY.
}

period of PP (pearl pulsations). If no PP occurred, the amplitude of the background was recorded. In the second step selected highquality samples of PP were digitized and placed on punched cards.

\section{Experimental Results}

Correlation with electrons. During the recording period six high-altitude balloon flights were made in an attempt to observe electron microbursts. On only one flight (September 8) was there sufficient electron precipitation to justify data reduction. On all flights except this one some PP occurred during the flight and at times of no electron precipitation. During the one flight when considerable electron precipitation occurred, particularly the microbursts described by Anderson and Milton [1964], no PP were detected.

This result is in general agreement with the lack of correlation between PP and other geophysical phenomena discussed by many observers. However, Troitskaya [1961] has suggested an association of IPDP (intervals of pulsations of diminishing period), with balloon observations of $\mathrm{X}$ rays. Tepley and Wentworth [1962] also suggest such a relationship based 


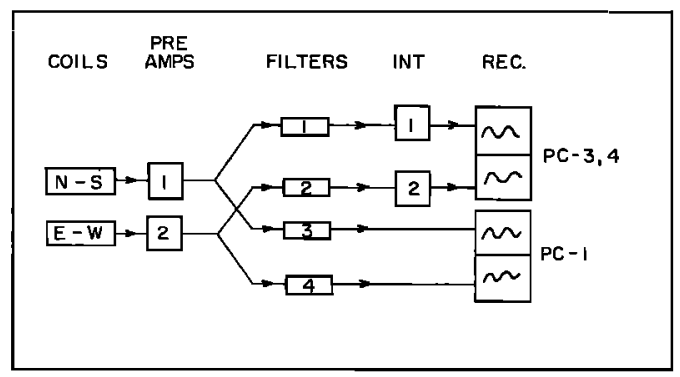

Fig. 1. Schematic diagram of magnetic micropulsation system used for studies made in the lower Pc 1 band.

on balloon and riometer observations. These examples seem somewhat anomalous, however, for both were made during sudden commencement (sc) events, which correspond to a minority of pearl occurrences. Campbell [1964] has made extensive observations of PP in the auroral zone during periods of simultaneous balloon flights. He sees no correlation between $\mathrm{PP}$ and $\mathrm{X}$ rays, even during periods of intense electron precipitation. Thus our results are in agreement with the most detailed observations made to date.

For the flight of September 8 an attempt was made to determine whether the amplitude of the $\mathrm{Pc} 1$ band background was related to the incident electron fluxes. Figure 3, based on 10-minute averages, shows no indication of a relationship on a gross scale. A more detailed comparison based on one-minute averages is given in Figure 4 for the most active hour of the flight. It is clear that there is no detailed correspondence. A further attempt was made to determine whether a difference existed in the $\mathrm{Pc} 1$ records between the two most active and the two quietest hours of this flight. The results do not

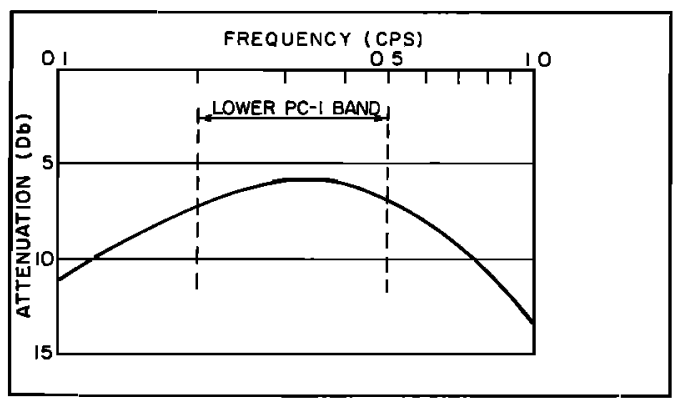

Fig. 2. Attentuation as a function of frequency for a typical bandpass filter used in recording the Pe 1 band. indicate any significant difference. Close visual examination suggests that the magnetic record, for this period band, may be slightly more erratic during electron precipitation, but not in any significant or easily described fashion.

Correlation with $A_{p}$ index. Preliminary examination of magnetograms obtained at Flin Flon during the recording period, as well as activity in the Pc 3, 4 band, seemed to indicate that PP occur during magnetically quiet times. Figure 5 compares the daily magnetic $A_{\text {, index }}$ with the daily total of the number of occurrences of $P P$ in 10-minute intervals. Half-hour occurrence data published by the Geophysical Institute, University of Alaska [Hessler, 1964] for the same period are also shown. It should be noted that there is little correspondence between the Flin Flon magnetic and College telluric results, despite the fact that Flin Flon and College are separated by only $1^{\circ}$ of magnetic latitude (Flin Flon $63.6^{\circ}$, College $64.7^{\circ}$; they are, however, separated by $58^{\circ}$ of magnetic longitude). It is also apparent that there is little general correlation between the occurrence of PP at Flin Flon and College and the $A_{p}$ index. However, a predominant enhancement of
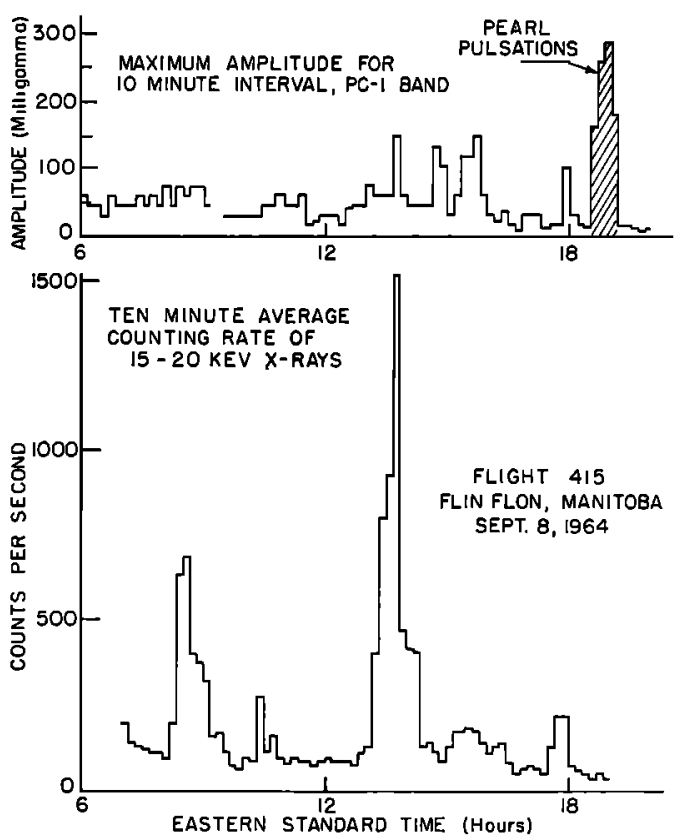

Fig. 3. Comparison of $\mathrm{Pc} 1$ amplitude in milligama as a function of local time with $15-20 \mathrm{kev}$ $\mathrm{X}$-ray counting rate. 
PP activity occurs both in the Flin Flon and in the College data on September 6. In the period following this date, there appears to be an inverse relation between $A_{2}$ and the number of occurrences of PP. It is particularly evident in the Flin Flon data. The linear correlation coeffcient between $A$, and the number of occurrences for the period before September 6 was found to be -.2 ; that for the later period was -.7 . The coefficient for the second period is quite high, having only a $1 \%$ probability of occurring by chance assuming a Gaussian distribution of errors. This result is of particular significance when it is noted that an sc occurred at 1355 local time on September 6 .

Considerable justification can be found in the literature for the assumption of a relationship between sc and PP. Troitskaya [1961] noted that PP were an element of the microstructure of magnetic storms. Tepley and Wentworth [1962] observed 6 cases of PP associated with sc out of 30 possible. Wentworth [1963], using several year's data, statistically established an enhancement of PP on the day of a magnetic storm, and a general increase in PP during the following week. Heacock and Hessler [1965]
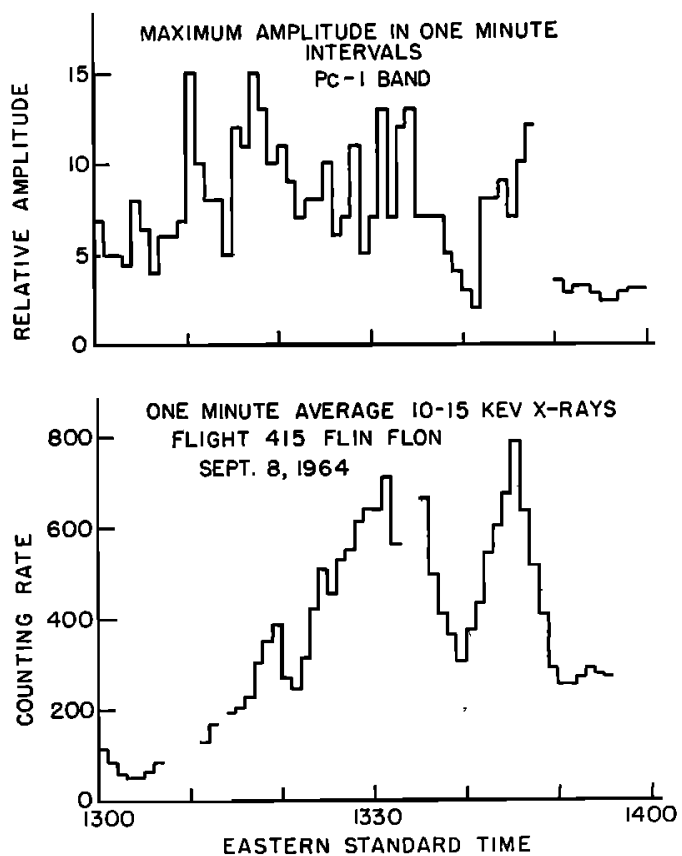

Fig. 4. Detailed comparison of X-ray counting rate and amplitude of $P c 1$ band micropulsations as a function of time. have performed a statistical analysis of the relation of PP occurrences and sc. They note an association about $50 \%$ of the time for sc occurring at all times of day. For sc occurring near times of peak PP occurrence the association is $80 \%$, and for sc near local noon there is essentially a $100 \%$ correlation. In addition they note a suggestion of an inverse correlation of $K_{p}$ and PP occurrence following sc.

Sudden commencement event of September 6,1964 . In view of the apparent relation discussed above between PP activity and the $A_{\text {p }}$ index following the sc, it seems important to examine this event in more detail. Records in both the $P c 1$ and $P c$ 3, 4 bands show interesting substructure which may have some bearing on a theory of the PP production mechanism. It should be noted that records taken for the Pc 3 , 4 bands were sensitive to PP events of large amplitude, since the limits of the bandpass filter used were 1-100 seconds period.

On the day of the sc event, 0-2400 CST, September 6,1964 , there were three major enhance-
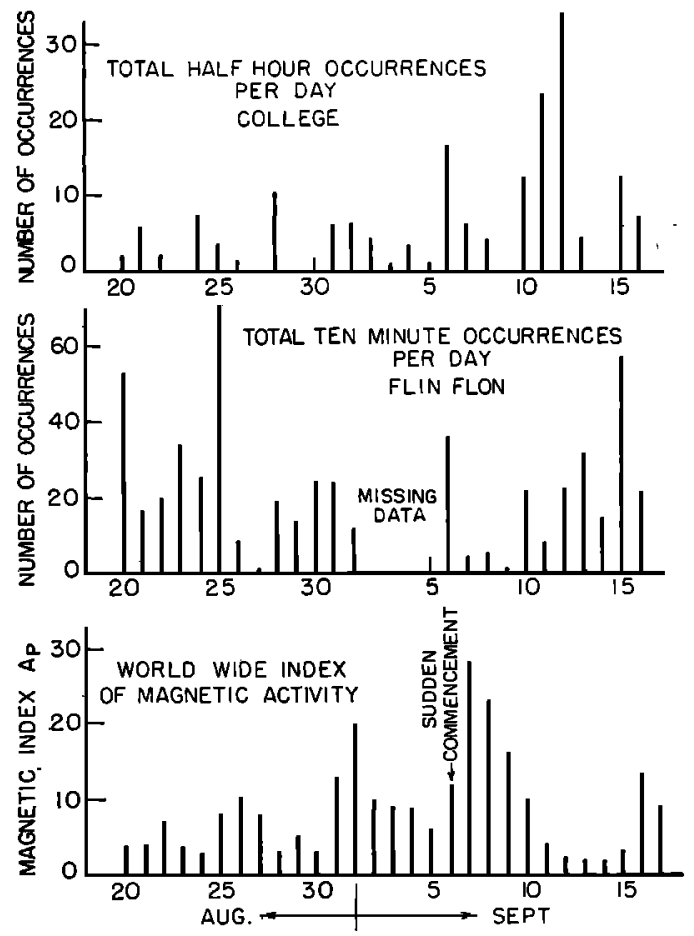

Fig. 5. Comparison of occurrences of pearl pulsations at College and Flin Flon with magnetic $A_{p}$ index for period August 20 to September 16, 1964 . 


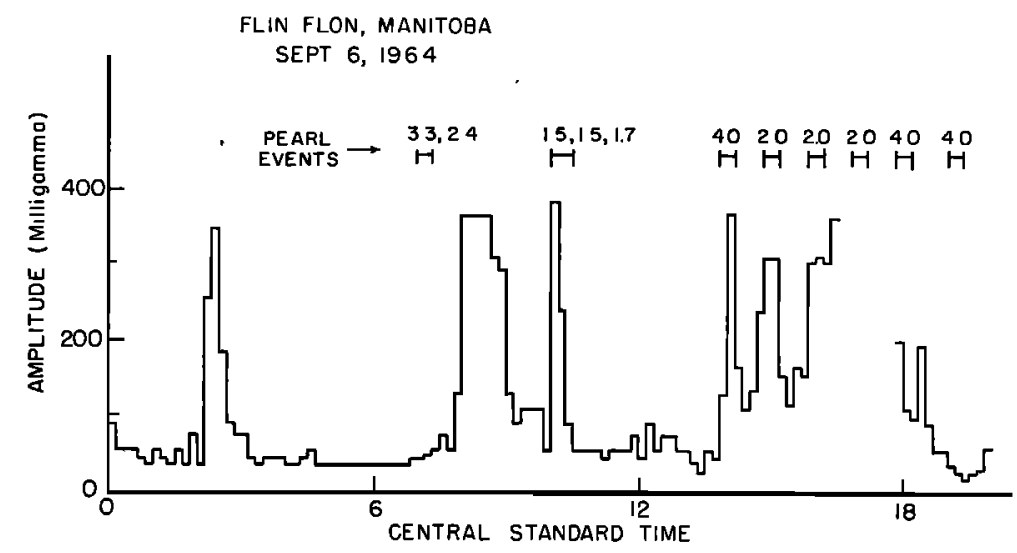

Fig. 6. Amplitude of Pc 1 band oscillations showing sudden commencement effects at 1955 UT September 6, 1964.

ments of activity in the Pc 1 band as shown schematically in Figure 6. These rose from a background of about 50 to more than $300 \mathrm{~m} \gamma$. The times of onset of these three events are separated by approximately 6 hours, the last coinciding with the sc at 1355 CST. The first event (0210 CST) was about an hour in length and had no associated PP. The second event $(0800$ CST) lasted 3 hours and had some associated PP. The PP occurring at the onset of this event had a period of about 3.0 seconds, and that at the end about 1.5 seconds.

The third event began at the sc and lasted for approximately 6 hours. Interpretation of the record with regard to the presence of PP activity is quite difficult, as there is no well-defined envelope. However, the periods are the same as $\mathrm{PP}$, and as the event progresses the envelope becomes more clearly defined and pearl-like. On this basis an examination of the records shows that PP began about 15 minutes before the sc with a gradual transition from short irregular pulsations of 4-second period to pearl-like signals of 1.5 -second period. Coincident with the sc there was an order of magnitude enhancement of erratic 4-second-period activity, with a suggestion that the signal faded to $100 \mathrm{~m} \gamma$. One hour after the sc (1450) there occurred a second comparable enhancement, but of the 2 -second background. Third and fourth 20-minute enhancements of 2 -second activity occurred at 1550 and 1650 . This hourly recurrence pattern continued for 2 more hours, with slight enhancement of the 4-second activity, where, however, the final two events assumed modulation envelopes characteristic of $P P$ activity.

The pattern of occurrence of pearl-like activity on five successive hours following the sc may be significant. In particular it suggests the possibility of particles drifting around the earth with a period of about 1 hour. Such a drift period, however, is incompatible with the production mechanism suggested by Cornwall [1965] involving 500-kev protons at 4 earth radii. Drift periods for these particles are of the order of 100 seconds. It would be of considerable interest to make a detailed comparison of the Flin Flon and College records to determine whether a similar pattern is observed in the College data. If the onset times at College were delayed by a factor corresponding to the difference in longitude between the two stations, the suggestion of a drift phenomenon would be verified and the periodic fluctuation in the production mechanism would be explained.

Particles drifting about the earth have been considered by a number of authors as a possible origin of PP. However, the periods involved are of the order of 1 minute rather than 1 hour. Jacobs and Jolley [1962] observed a westward drift of $15^{\circ}$ per hour, suggesting a pattern of occurrence fixed with respect to the sun. Heacock [1963] attempted to interpret Alaska data in terms of a fixed spiral pattern of PP occurrence. Examination of data for November 22, 1961 , published in his paper, suggests on one occasion a series of hourly occurrences of PP similar to that discussed in the present paper. 
In general this hourly repetition of pearl-like events does not seem to have been examined previously.

\section{Average Characteristics of PP Events FoLLOWING THE SC}

The average characteristics of pearl activity following the sc magnetic storm of September 6 were examined. The results are shown in Figure 7. As discussed above, the inverse correlation between the $A_{p}$ index and the occurrence of PP stands out clearly. There also appears to be a general increase in the period and amplitude of PP for several days following the sc for the few $P P$ events that did occur. This increase is followed by a considerable decrease, reaching a minimum on the fifth day, with a slow recovery toward average in the next 5 days.

Since this was the only magnetic storm that occurred during the recording session, it it not known whether or not this is a typical example.
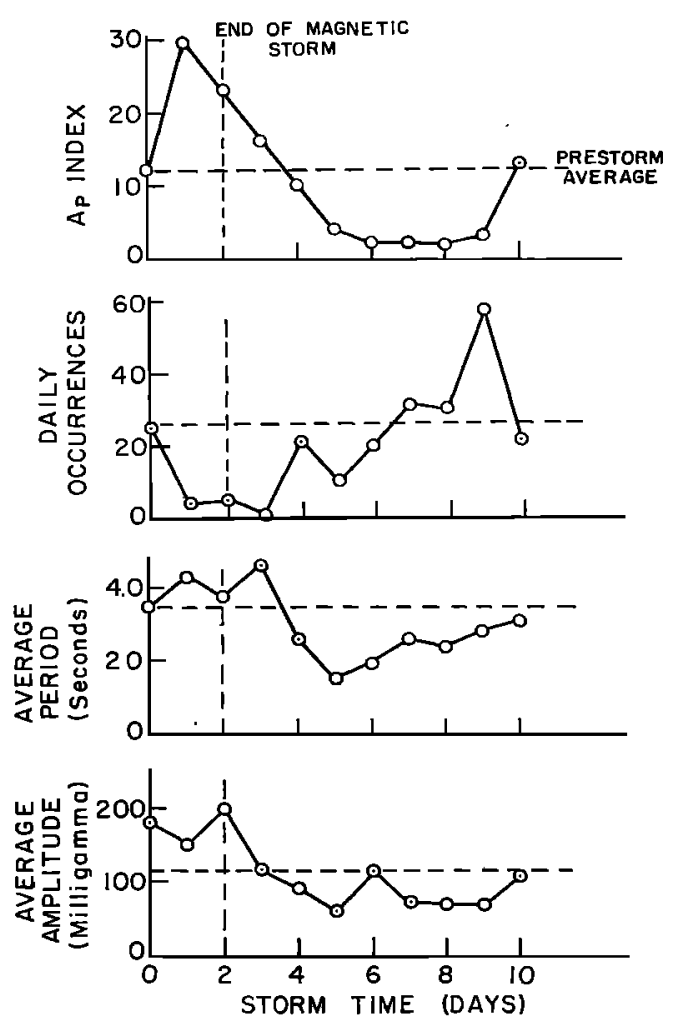

Fig. 7. Average characteristics of pearl pulsations following sudden commencement magnetic storm of 1944 UT September 6, 1964, observed at Flin Flon, Manitoba.
An attempt was made to find similar characteristics in College PP data. No such systematic behavior was noted, even for the same event. Comparison of the Flin Flon and College data below indicates that the College telluric system is only about half as sensitive as the system used in this experiment, which may account for the lack of agreement of the Flin Flon and College data in this respect.

\section{Statistical Characteristics of $P P$}

General. Information obtained from the logging of the Flin Flon records has been processed on IBM tabulating machines, and average characteristics of PP have been determined. Data published by the Geophysical Institute, University of Alaska, have been handled in the same fashion. The data have been normalized whenever possible, and the results have been expressed as relative frequency or probability of occurrence. These terms are loosely defined as

Probability of occurrence $=100$

Number of occurrences

Number of possible occurrences

The relative frequency with which pearl events of various period occurred in the intervals August 20 to September 16 at Flin Flon and January 1 to July 1 at College are shown in Figure 8 . The ranges of periods observed were mainly between 1 and 5 seconds. There is considerable difference in the two distributions, the median periods being about 31 seconds at Flin Flon and 1.8 seconds at College. The similarity of the Flin Flon distribution to the characteristics of the filter passband should be examined. As is shown below, the majority of PP events observed are of low amplitude. The rapid increase in attenuation (7-12 db) exhibited by the filter at periods shorter than 2.0 seconds suggests that a number of $\mathrm{PP}$ events in this range may be reduced in amplitude below the constant background of short irregular pulsations. Hence the lack of agreement with the College data may possibly be instrumental for periods shorter than 2 seconds. However, the general trend of the Flin Flon data in the region 2.0-3.0 seconds, in which attenuation is almost constant, does imply a peak at 2.7 seconds. Without detailed knowledge of the College passband, no definite statement can be made about 

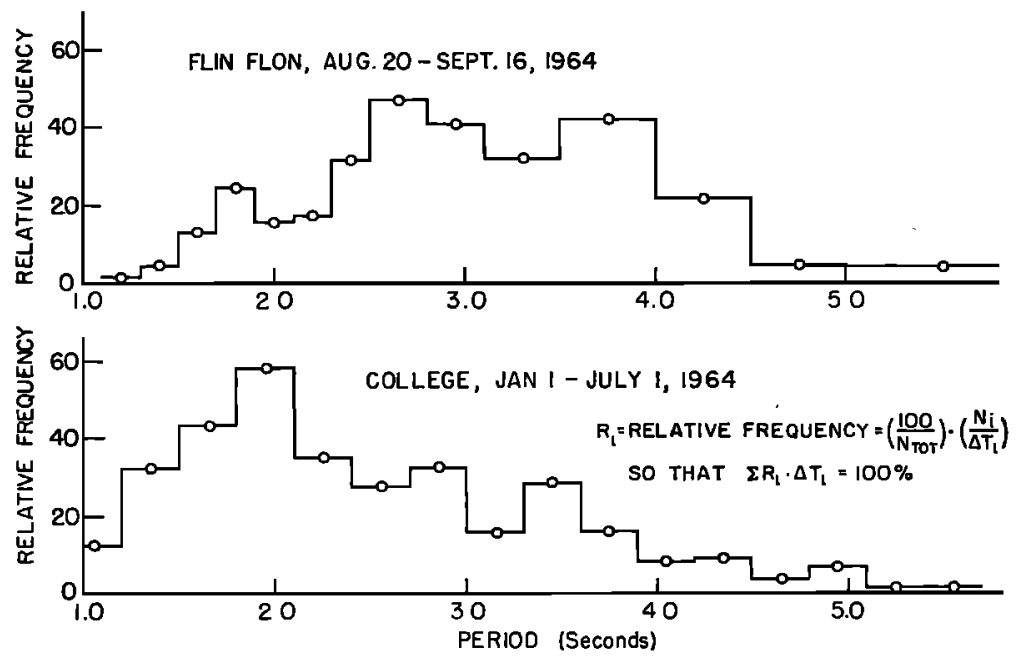

Fig. 8. Relative frequency of occurrence of various periods of pearl pulsations as a function of period for indicated intervals, Flin Flon and College data.

the significance of the differences in the two distributions.

The frequency distribution of observed PP amplitudes is shown for Flin Flon and College in Figure 9. Both distributions show approximately exponential falloffs with amplitude. Twenty per cent of the PP events observed at Flin Flon had amplitudes between 25 and 50
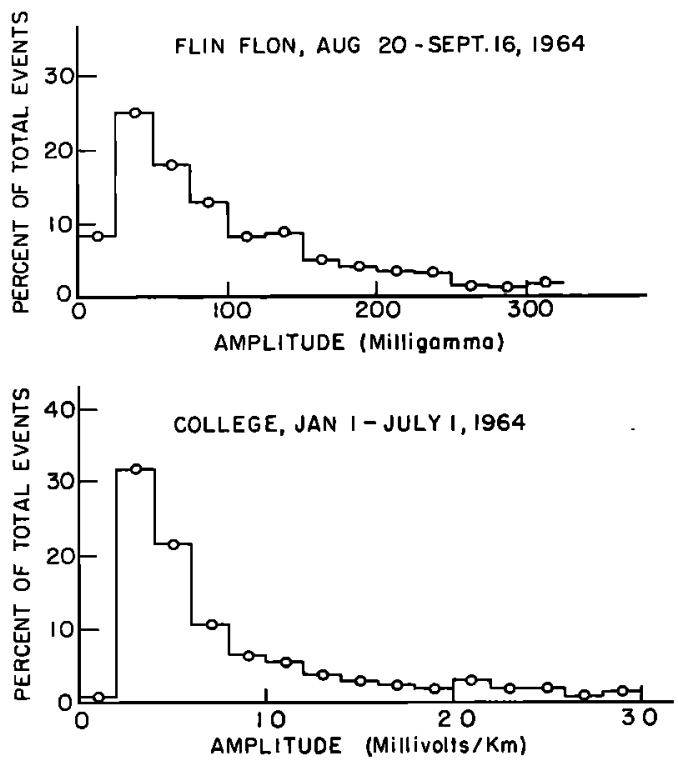

Fig. 9. Frequency of occurrence of various amplitudes as a function of amplitude for indicated intervals, Flin Flon and College data. $m \gamma$, the largest-amplitude event observed being $800 \mathrm{~m} \gamma$. The low probability of observing PP less than $25 \mathrm{~m} \gamma$ at Flin Flon is not instrumental. The system noise level was approximately 0.5 $\mathrm{m} \gamma$. Instead this result is a consequence of the steady noise background of short irregular pulsations. Typically these have an amplitude of 10-20 $\mathrm{m} \gamma$ during quiet times. As a consequence, it becomes very difficult to identify a $P P$ event on an amplitude time recording. A comparison of the two curves suggests that College telluric signals of $10 \mathrm{mv} / \mathrm{km}$ are comparable to $100-\mathrm{m} \gamma$ magnetic signals.

The times of occurrence of PP are highly dependent on local time, as is shown in Figure 10. On the average, PP were observed during $17 \%$ of the possible 10-minute intervals at Flin Flon. The most active period was 1400-1500 Imt with PP occurring $50 \%$ of the time. By comparison the most active period at College was 1500 $1600 \mathrm{lmt}$ with PP 25\% of the time. The difference in the maximum frequency of occurrence at the two stations suggests that the equipment at Flin Flon was considerably more sensitive than that at College.

The period of PP also appears to be a function of local time as shown in Figure 11 for both Flin Flon and College. A minimum period occurs before sunrise and a maximum period after sunset.

There is some suggestion of a similar local time dependence in the amplitude, at least for 

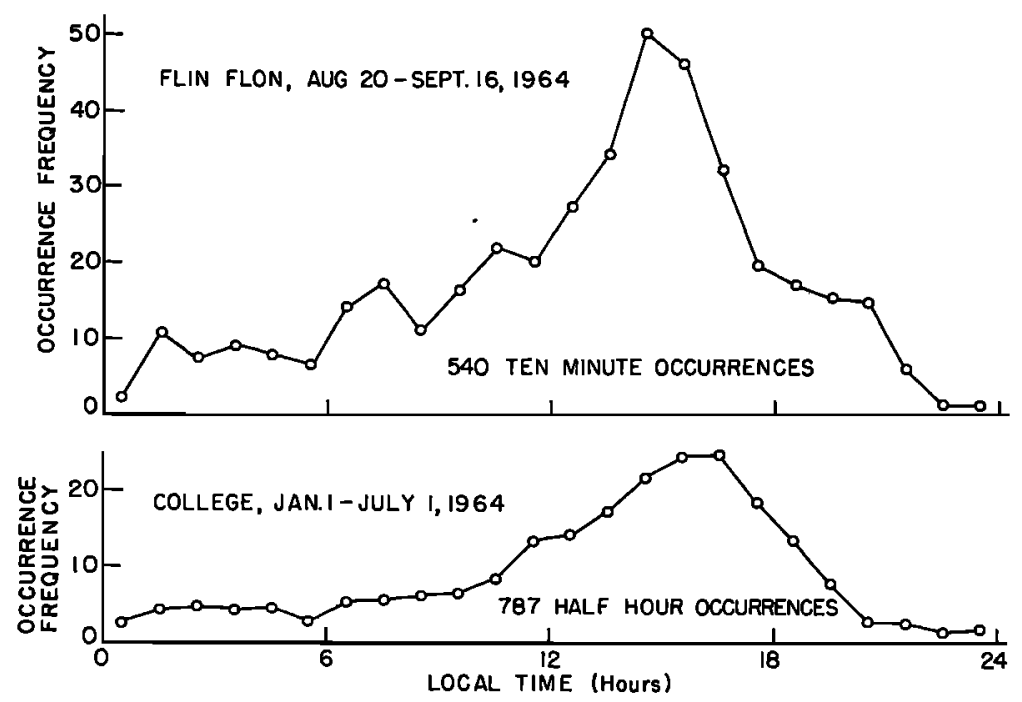

Fig. 10. Frequency of occurrence of pearl pulsations as a percentage of possible occurrences plotted as a function of local time for indicated intervals, Flin Flon and College data.

Flin Flon. There is a definite enhancement of amplitude near the middle of the day for both locations, as the data of Figure 12 indicate. It is interesting to note that the enhancement at College follows (in local time) that at Flin Flon by about 2 hours. Clearly the effects of geomagnetic latitude and longitude need to be evaluated.

Correlation with $K$ indices. An attempt was made to correlate the occurrence of PP during a 3-hour interval with the value of the magnetic $K_{p}$ index. When all data were taken into consideration and normalized, it was found that the probability of occurrence of PP at Flin Flon or College was not a function of $K_{p}$. This should be contrasted to the more local index $K_{00}$ at College which shows a general decrease in the probability of occurrence with increasing $K_{\mathrm{oo}}$. This is shown in Figure 13, for which no PP events were observed at College for $K_{c o}>5$. It is not clear whether the apparent enhancement of PP occurrence for $K_{p}=6$ at College is real or simply reflects poor statisties.

Although the occurrence of PP does not seem to depend on $K_{p}$, it is possible that some other characteristics of PP does. To examine the possibility, the data were separated into groups depending on the value of $K\left(K_{\mathrm{g}}\right.$ at Flin Flon and $K_{\text {oo }}$ at College). It was found that the time of occurrence of PP does depend on $K$ as shown in Figure 14. For $K=0$ the occurrence is rather well distributed throughout the day with a broad maximum about local noon. For $K=1$ the probability of occurrence in the morning is slightly decreased, whereas there is a slight enhancement in the afternoon. This characteristic is still more evident for $K=2$, particularly in the Flin Flon data. For $K=3$ there are insufficient data from Flin Flon. However, the College data verify the trend as shown for $K=$ 3,4 , and 5 . In summary, we note that, as $K$ increases, the peak probability of occurrence of PP comes later and later in the afternoon; that the times of occurrence of PP becomes more and more limited; and that the probability of occurrence is considerably enhanced at the most probable time of occurrence.

Figure 15 indicates a very slight dependence of period on the $K$ index. There appears to be a tendency for longer-period events to be associated with higher values of $K$. Figure 16 seems to indicate a more significant dependence of amplitude on $K$, showing an association of higher amplitudes with higher $K$ values. In addition it was found that, for all values of $K$, there is an association of longer periods with higher amplitudes.

Quality of PP. During the logging procedure a quality figure was assigned to each 10minute interval during which $P P$ occurred. It was based on a four-point scale, 1 corresponding 


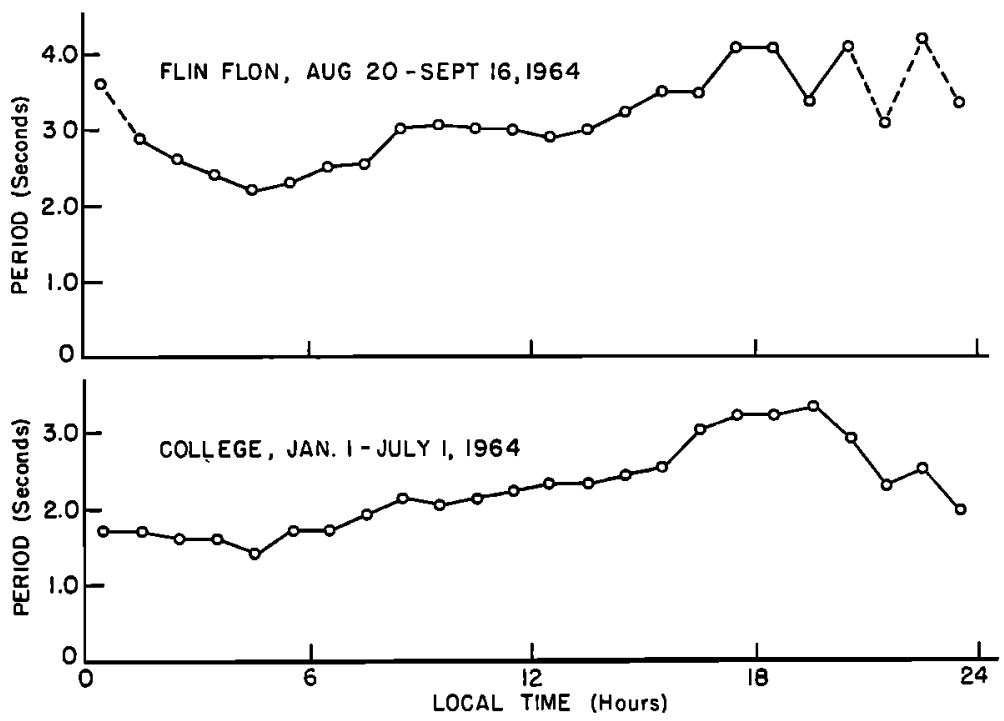

Fig. 11. Average period of pearl pulsations observed during indicated intervals as a function of local time for Flin Flon and College data.

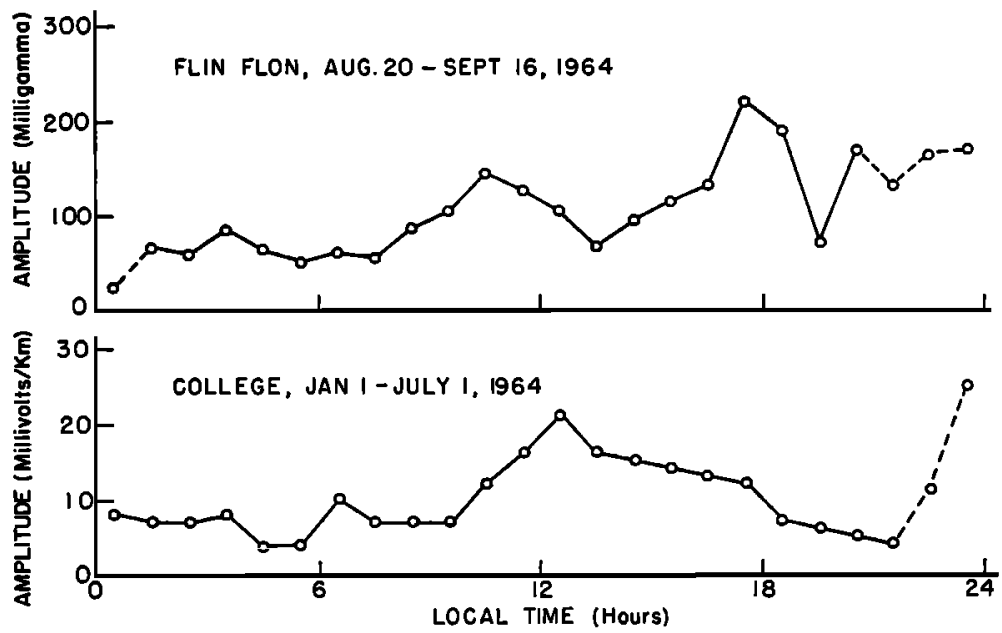

Fig. 12. Average amplitude of pearl pulsations observed during indicated intervals as a function of local time for Flin Flon and College data.

to the lowest- and 4 to the highest-quality $P P$ events. The figure was determined subjectively on a basis of the degree of uniformity and regularity of the fundamental oscillation and its modulation envelope. If PP are caused by hydromagnetic waves propagating along field lines, a high quality figure may indicate that the particular event is associated with field lines originating near the recording station. It was found that highest-quality PP events tend to occur earliest in the local day and have more limited ranges of periods and amplitudes. The tendency is illustrated in Figures 17, 18, and 19.

Polarization of pearl pulsations. Selected 3-minute samples of well-defined PP events were digitized at intervals of 0.75 second and placed on punched cards. The data were read into a computer and broken into five 37.5-second segments per sample. Initial computer output included, for each segment, a plot of the azimuth of the magnetic perturbation vector as a function of time, and a scatter diagram representing the lo- 

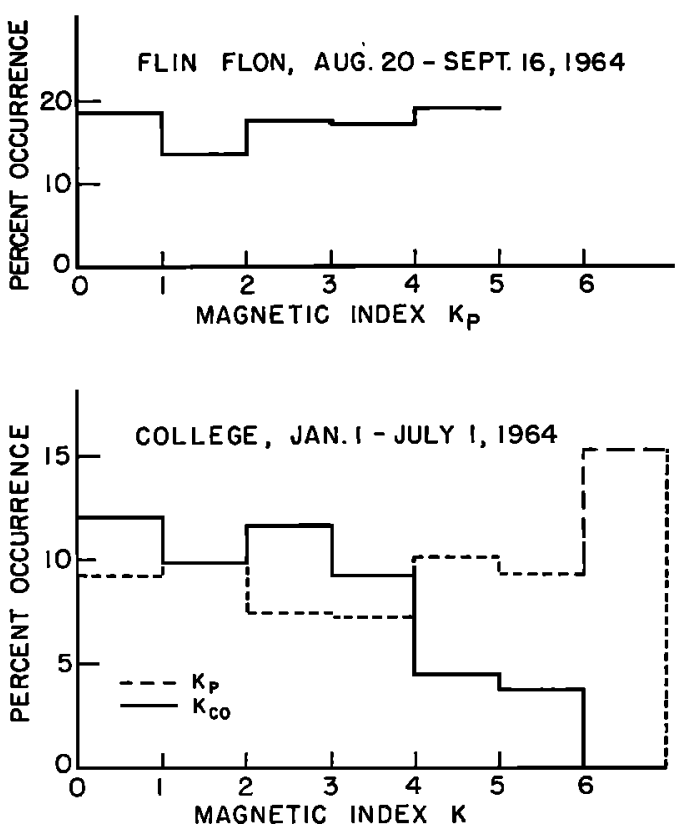

Fig. 13. Percentage of intervals having a given value of the magnetic $K$ index during which pearl pulsations occurred.

cus of positions of this vector in the horizontal plane. A rough ellipse was drawn to include almost all points, and its azimuth from magnetic north and axis ratio was measured. The average direction of rotation was determined for the segment by counting the number of clockwise and counterclockwise rotations. The average azimuth and axis ratio for the sample was obtained by taking the average of the results for the five segments. A measure of the variability of these two quantities was found by determining the standard deviations of the five determinations of each quantity from their averages. Data samples were taken from as many hours, on as many days, as was possible. Twenty samples have been studied in this fashion. After the preceding analysis, the computer program was modified to include a least-squares analysis of the ellipse characteristics, computed so that half the data points fell inside the resulting ellipse. Seventeen additional data samples were subjected to this analysis.

From this information it is possible to conclude that there is a tendency (2 to 1) toward predominantly clockwise rotation (right circu- larly polarized for a downward propagating wave, in the northern hemisphere, viewed along the wave normal), and also that there is a tendency for the azimuth of the polarization ellipse to be oriented approximately $35^{\circ}$ east or west of magnetic north. The latter tendency is illustrated in Figure 20. Beyond these facts there appears to be no obvious systematic behavior. The direction of rotation does not depend on azimuth, time of day, or period of oscillation in any apparent fashion. Neither does the azimuth seem to depend on time of day or period.

The lack of systematic behavior may possibly be accounted for in one of the following ways. One explanation would be that irregular and diurnal variations of ionospheric characteristics are so great that systematic effects in the PP polarization ellipse are washed out. A second possibility may be related to the fact that PP are not necessarily incident normally on the earth, so that the observed ellipses are a projection into the horizontal plane. As the angle of incidence changes, the azimuth of this projected ellipse also changes.

In addition to the above, an attempt was made to determine whether the detailed characteristics of the polarization ellipses were similar to those reported by Pope [1964]. A 10-minute sample of well-defined pearls was examined in 12-second segments. The azimuths of the resulting ellipses were constant during the entire period within $\mp 2^{\circ}$, and the ratio of major to minor axis remained almost a constant 5.0. Linear polarization developed during one segment of the record, but no 'beating ellipse,' with continuous changes in eccentricity, or switches in the direction of the major axis occurred. This relative constancy of azimuth and ellipticity is illustrated, for the 10-minute sample, in Figure 21. The characteristics as determined by small segments of the record persisted during a period of at least 30 minutes following the above 10-minute segment.

In contradiction to this behavior one case has been examined in which the azimuth of the polarization ellipse changes over $90^{\circ}$ in less than 1 second. A detailed examination of the records shows that this is a consequence of an approximately $90^{\circ}$ phase shift in the north-south component of the magnetic field. About 30 seconds later a similar variation returns the azimuth to the original direction. Thus we have not con- 

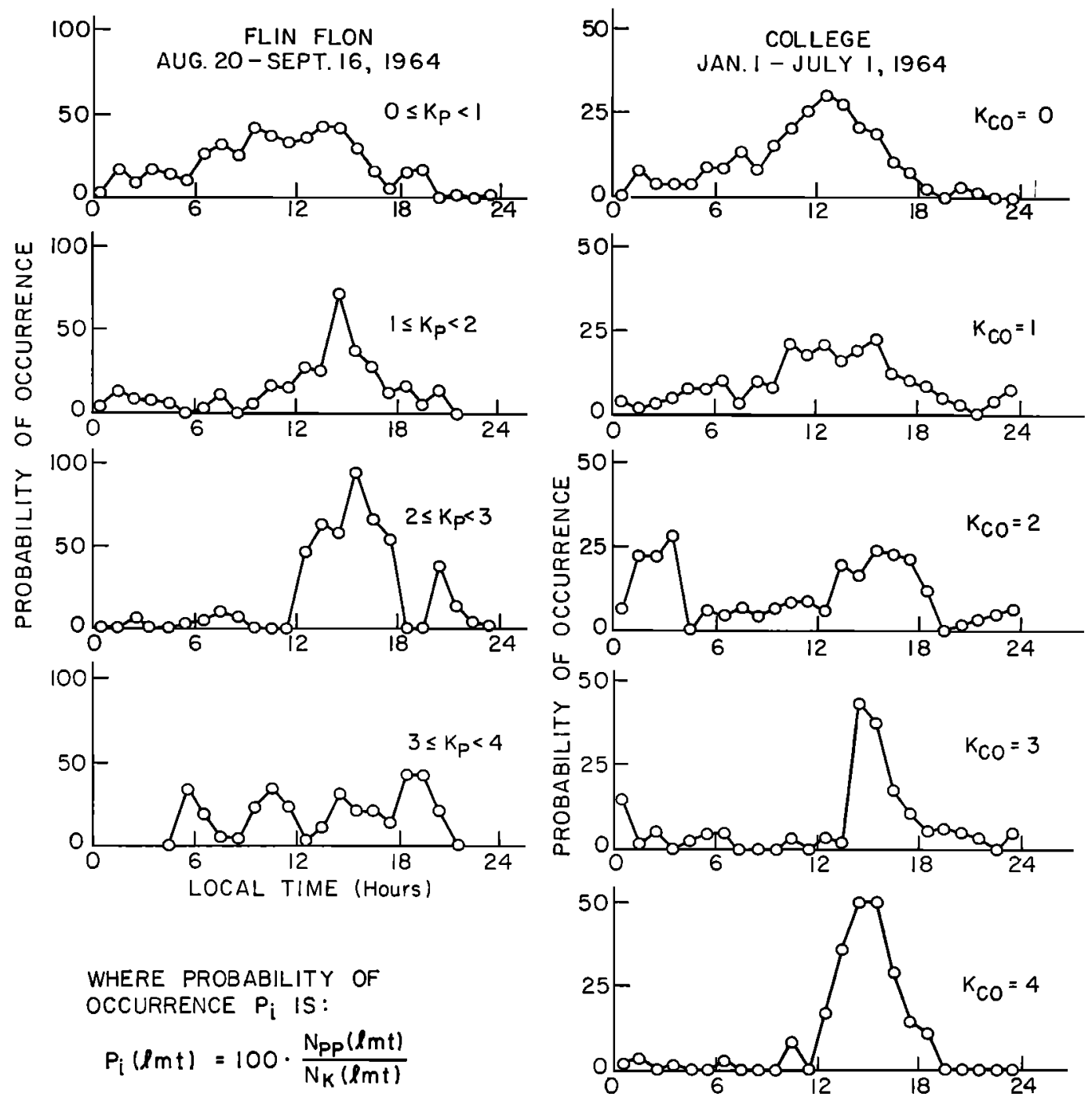

WHERE PROBABILITY OF OCCURRENCE $\mathrm{P}_{\mathrm{i}}$ IS:

$$
P_{i}(l m t)=100 \cdot \frac{N_{P P}(l m t)}{N_{K}(l m t)}
$$

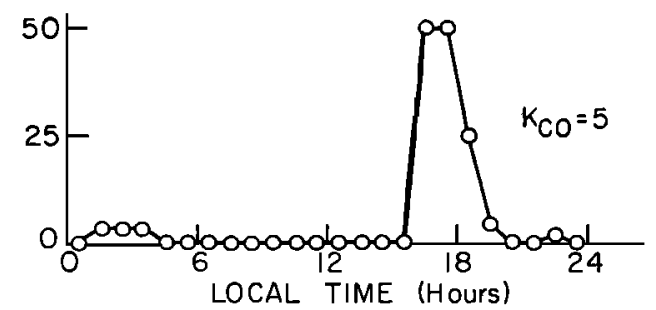

Fig. 14. Probability of occurrence of pearl pulsations during a given hour having a specified magnetic index $K$, as a function of local time. 

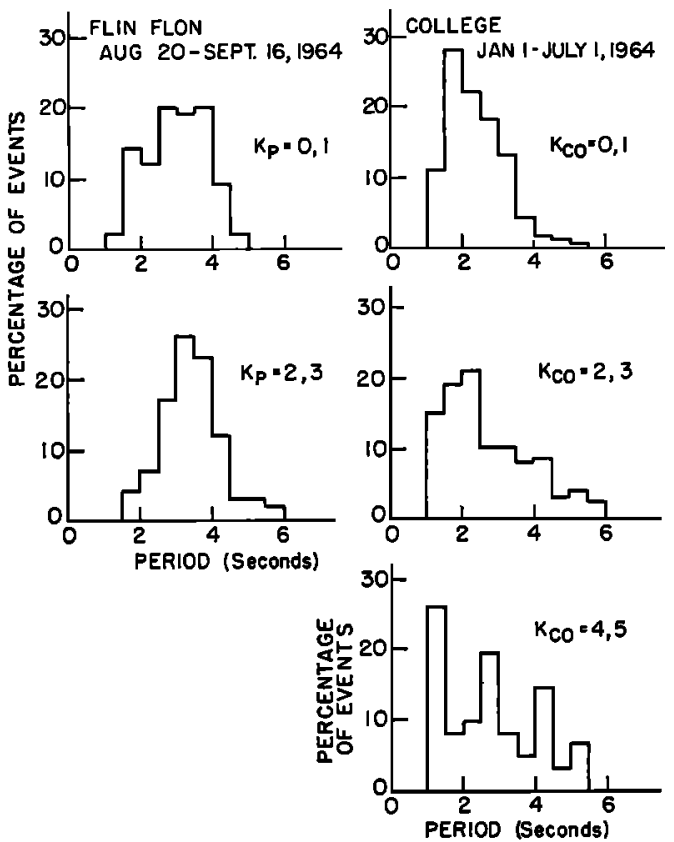

Fig. 15. Percentage of total number of pearl pulsation events occurring during intervals of given $K$ index which have a specified period.
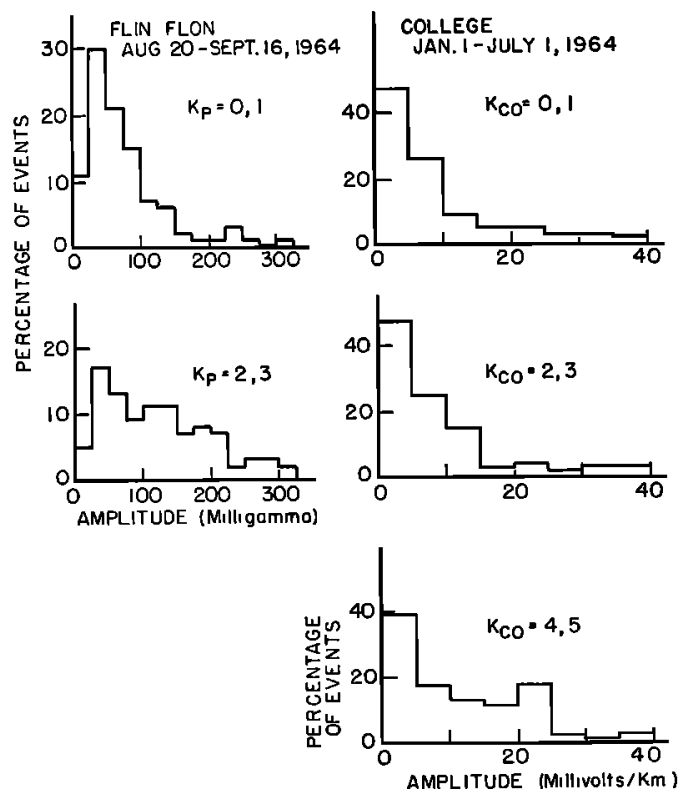

Fig. 16. Percentage of total number of pearl pulsation events occurring during intervals of given $K$ index which have a specified amplitude. firmed Pope's observation of transitional change from counterclockwise to clockwise rotation.

Pope demonstrated that this transitional change could be accounted for by superposing the polarization ellipses due to two different rising tones with major axes of different azimuths. However, one should not attempt to draw the implication from Pope's paper that the two superposed ellipses necessarily have any reality in terms of some of the mechanisms suggested for the origin of pearls. For example, if pearl pulsations are a result of the proton cyclotron resonance mechanism suggested by Cornwall [1965], each rising tone should be a left circularly polarized wave when incident on the ionosphere. The effect of the anisotropic ionosphere will be to introduce a right circularly polarized component, which produces elliptical polarization at the surface of the earth. If we
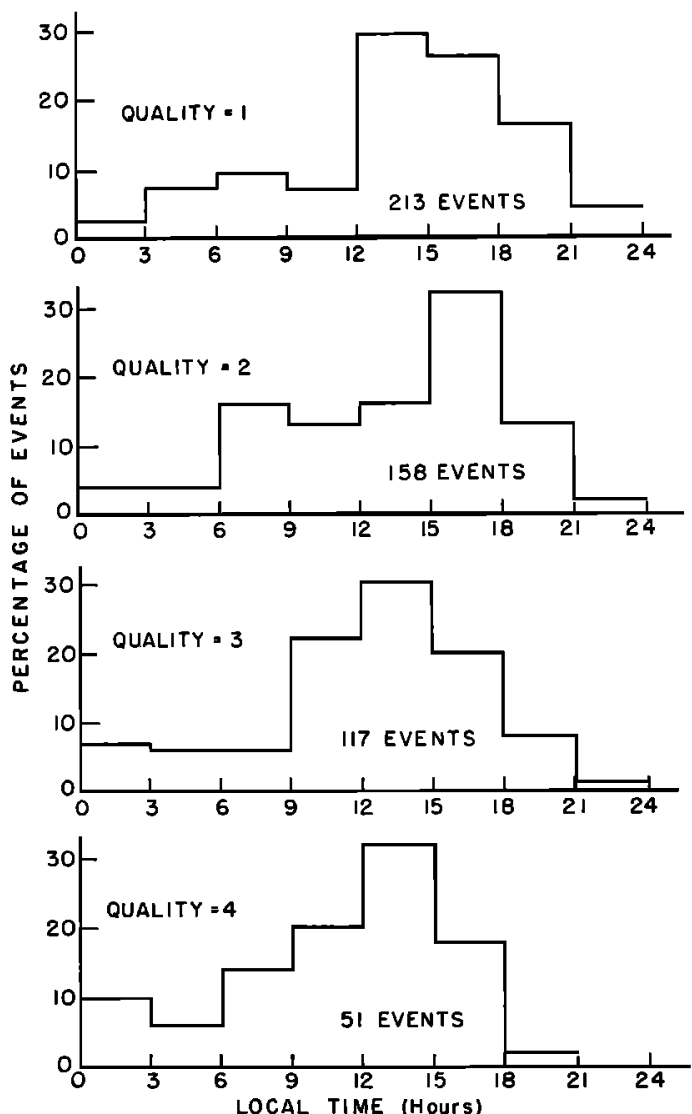

Fig. 17. Probability of occurrence as a function of local time and quality factor. 

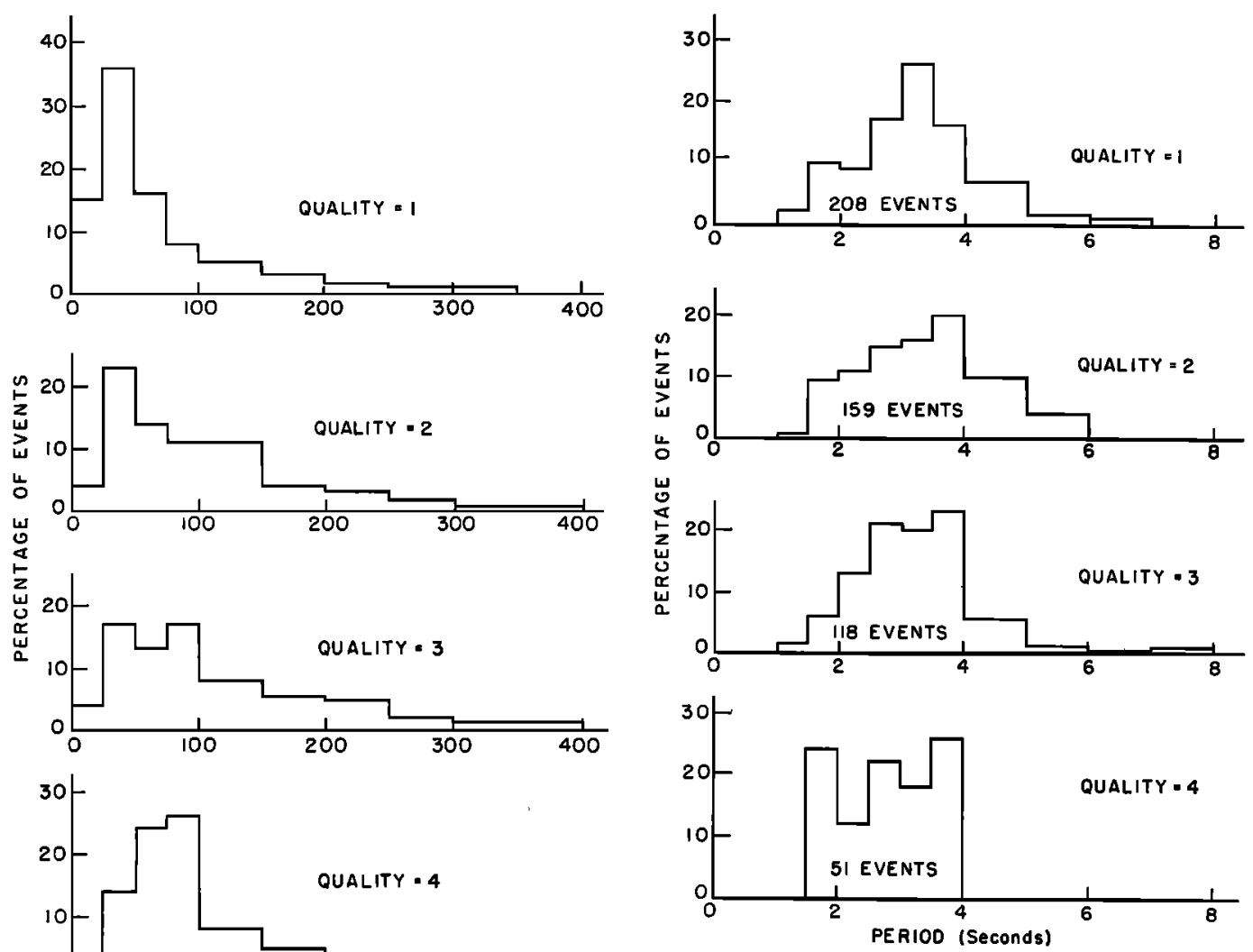

Fig. 19. Probability of a given period as a function of pearl envelope factor.

Fig. 18. Probability of a given amplitude as a function of pearl envelope quality factor.

now add two rising tones of very small frequency difference, the effect of the ionosphere on one tone is nearly identical to that on the other, and the resulting ellipses of polarization will be practically identical. Under this circumstance, superposing the two tones will not lead to a reversal in sense of the resultant ellipse as Pope clearly indicates.

Correlation with Pc 3, 4 band activity. We have seen that the probability of occurrence of PP is not related to the $K_{p}$ index, but that the time of occurrence of PP and possibly the period of PP depend on the $K_{p}$ index. It is entirely possible that $K_{p}$, being a mean 3-hourly range index, is too coarse a measure of geomagnetic activity. As an alternative measure we might use Pc 3, 4 band activity (10- to 150 -second period). To investigate this possibility we pre-

pared Figure 22, from which can be noted the following:

1.(a) Pe 3, 4 band activity (including $\mathrm{Pi}$ 2) on slightly disturbed days $\left(\Sigma K_{p}>15\right)$ peaks strongly near 0100 local time and is generally strong between 2300 and 0500 . (b) For disturbed days ( $Z \leq K_{p} \leq 3$ ), PP activity is extremely low whenever $\mathrm{Pc}_{\mathrm{c}} 3,4$ activity is strong. Comparison of curves $C$ and $D$ reveals very nearly an inverse correlation.

2.(a) Pe 3, 4 band activity on quiet days $\left(\Sigma K_{\mathrm{p}}<15\right)$ peaks weakly at about 0100 and 0430 , corresponding to peaks on disturbed days, but also exhibits a broad peak over the hours 1200-1800. The peak at 0100 corresponds to $\mathrm{Pi}$ 2, that at 0430 corresponds to some spectral overlap from the Pc 5 band, and the broad afternoon peak corresponds to the usual Pc 3, 4 diurnal peak. Reference to articles by Saito [1964] and Romana and Cardus [1962] has facilitated these identifications. (b) PP activity 
DISTRIBUTION OF AZIMUTHS

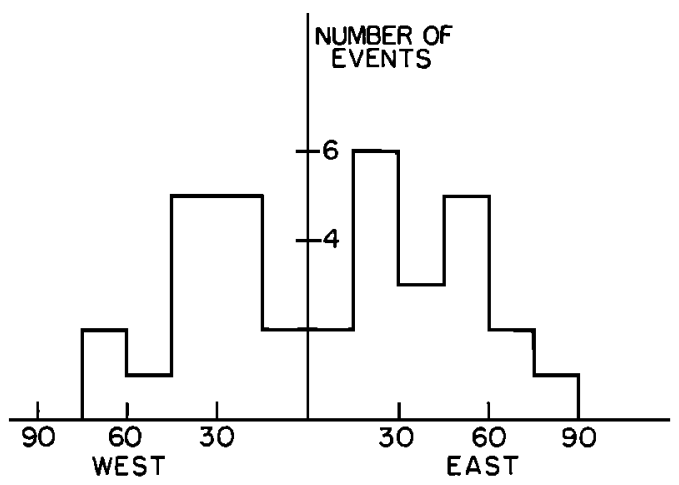

DISTRIBUTION OF MAJOR-MINOR AXIS RATIO

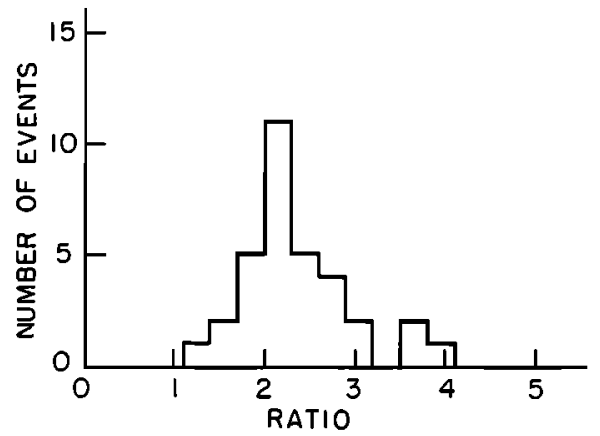

Fig. 20. Distribution of azimuths and major to minor axis ratio for pearl pulsation polarization ellipses.

during quiet days $(0 \leq K<1$ ) occurs generally throughout the day from 0600 to 1800 and there does not appear to be any simple correlation with $\mathrm{Pc} 3,4$ activity. Apparently the magnetic activity is sufficiently low to permit observation of PP whenever a driving mechanism exists.

3. The frequency of occurrence of PP for all days does not correlate in detail with $\mathrm{Pc} 3$, 4 activity. Generally the PP activity is lowest when $\mathrm{Pc} 3,4$ band activity is highest between the hours of 0200 and 2000 . The PP occurrence curve for all days corresponds reasonably with that found for College by Heacock and Hessler [1965]. For this type of study, the Pc 3, 4 activity seems to be a much finer measure of geomagnetic activity than the $K$ index. It should be appreciated that all the above deductions apply to an auroral-zone station.

\section{Discussion}

Correlations. Heacock and Hessler [1965] have noted that 'ssc is the only geophysical phenomenon for which a relationship to pearls has been conclusively established.' To this comment we should like to add the following, which pertain to auroral-zone observations:

1. There is no correlation of PP with electron precipitation.

2. PP-type activity occurs at the time of an sc and can have an hourly repetition of occurrence for 5 or 6 hours thereafter.

3. The $K_{p}$ index is too coarse for adequate representation of geomagnetically disturbed times when studying the dependence of PP occurrence on geomagnetic activity, but the occurrence of PP is clearly related to the local $K$ index.

4. There may be a slight dependence of PP period on $K$, longer periods being associated with higher values of $K$.

5. PP have higher amplitudes when $K$ vallues are higher.

6. The period of $P P$ increase through the local day from a minimum before sunrise to a maximum at sunset.

7. The time of occurrence of $P P$ is clearly related to the $K$ index. For low $K, \mathrm{PP}$ are distributed throughout the daylight hours, with a peak about noon. As $K$ increases, the occurrence time shifts to peak at $1800 \mathrm{LMT}$ and in fact to be redistributed to about a three-hour interval around $1800 \mathrm{LMT}$ by the time local $K$ reaches 5 .

8. Pc 3,4 band activity may be used as a good predictor for PP occurrence, since, for days rated as disturbed by $\mathrm{Pc} 3,4$ activity, there is an inverse correlation between PP and Pc 3, 4. For days rated as quiet by Pe 3, 4 activity, PP may occur at any time during the daylight hours.

The above correlations may very well be of importance in deducing the mechanism for PP production. Before discussing the significance of these features in relation to source mechanisms, we should like to add one more conclusion, i.e., that the polarization of pearls we have observed cannot be derived from any simple mechanism of the superposition of two rising tones, as Pope observed. Nor can Pope's explanation of his observations be extended to seek consistency with Cornwall's theory of the origin of PP as 

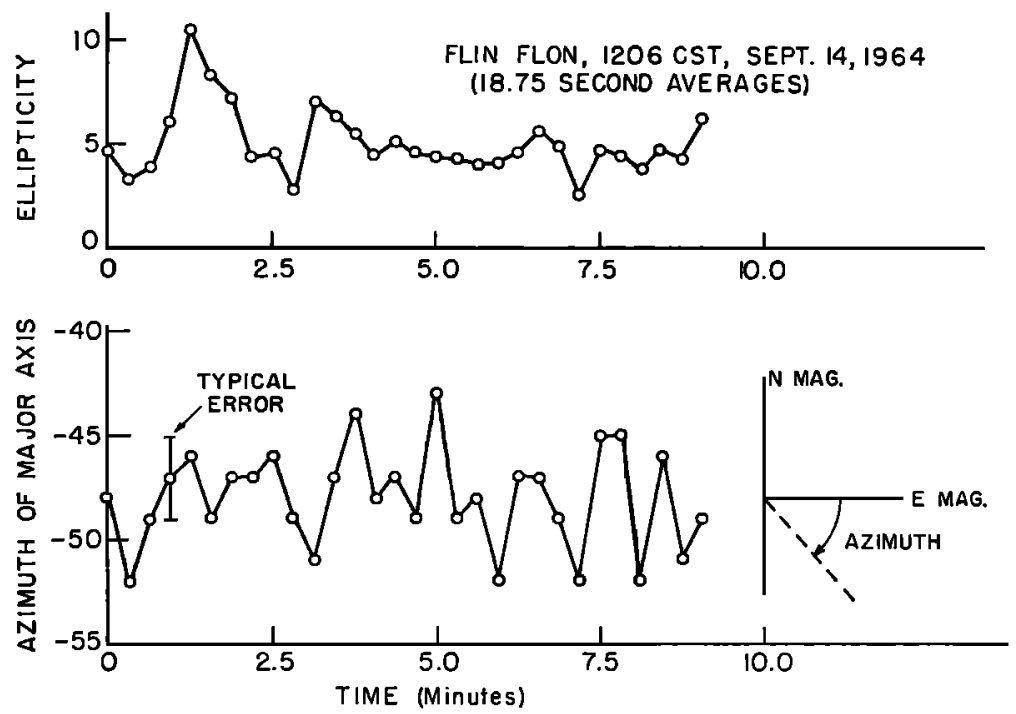

Fig. 21. Constancy of azimuth and ellipticity for 10-minute sample of well-defined pearls.

the result of a proton cyclotron resonance mechanism.

Interpretations. The most recent suggestions of mechanisms responsible for pearl pulsations are hydromagnetic in nature and very similar to those suggested for VLF emissions. An examination of these suggestions shows that there are four major problems to be studied: (1) transmission of PP through the ionosphere; (2) mechanism for guiding hydromagnetic wave packets along field lines; (3) mechanism for amplification of $\mathrm{PP}$ in a dissipative medium; and (4) source of magnetic disturbance which triggers the hydromagnetic wave packet.

The most likely explanation of PP seems to be that hydromagnetic radiation given off by recently trapped particles is amplified by a cyclotron instability in the plasma, is then guided along a field line due to the nature of the particular hydromagnetic wave mode, and is attenuated in passing through the ionosphere. At present little is known of the temporal behavior of any of the aspects of this problem. Consequently it is not obvious how the characteristies of PP observed in this experiment are related to the model outlined above. Interpretations of some of the observed facts are suggested in the following paragraphs.

One possible interpretation of the average characteristics of PP following the sc Figure 7 can be based on attenuation. It is assumed after
Akasofu [1964] that high values of the $A_{p}$ index are caused by the presence of auroral electrojets. In particular it is assumed that particle precipitation during 'stormy' times causes enhanced ionization in the auroral ionosphere. The low probability of occurrence of PP during times of high magnetic activity following the sc is thus attributed to attenuation in the lower ionosphere. The initial increase in period is accounted for by the fact that shorter periods are attenuated more than longer periods. The following interval of smaller than average period would then result from enhanced transmission during times of relatively little disturbance.

The initial increase in amplitude is not easily interpreted in terms of attenuation but is probably due to a stronger source mechanism. However, the days of lower than average amplitude may be explained by noting the distribution of amplitudes of PP events in Figure 9. This distribution is peaked at very low values. Thus, as attenuation disappears with the magnetic disturbance, a large number of low-amplitude signals are transmitted and weight the average heavily.

The contrasting dependence of PP occurrence on the local $K$ index and the worldwide $K_{p}$ index (Figure 13) may also be interpreted in terms of attenuation. We assume as above that higher $K$ values are indicative of enhanced ionization. If so, the decreasing probability of PP 

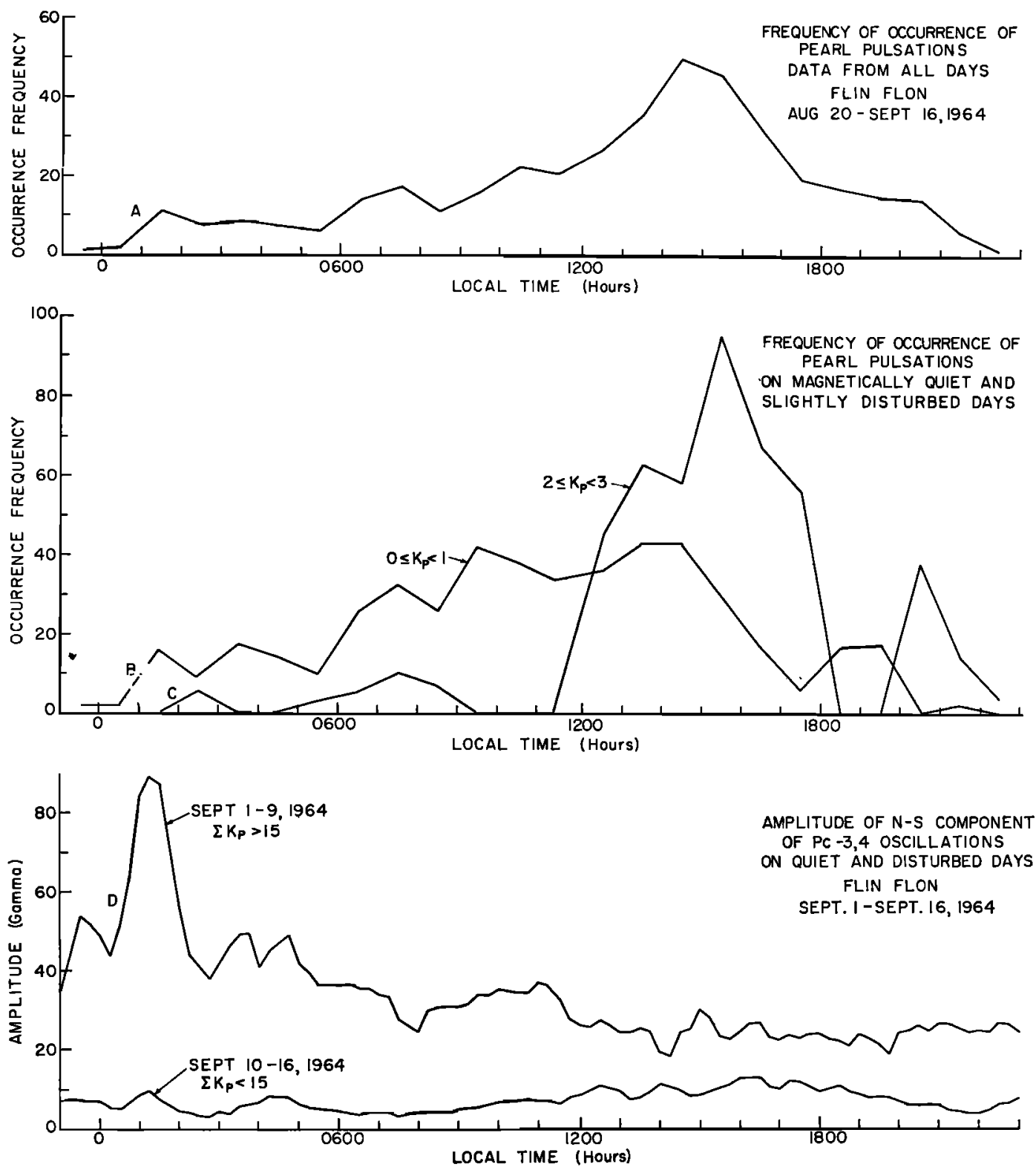

Fig. 22. Comparison of the occurrence of pearl pulsations with the amplitude of $\mathrm{Pc} 3,4$ oscillations as a function of local time for magnetically quiet and disturbed times.

occurrence with increasing $K$ index indicates that fewer PP events are transmitted through the ionosphere during locally disturbed times. That a similar dependence on $K_{p}$ does not occur is probably related to the fact that PP occurrence is not generally a worldwide phenomenon (from local time dependence). PP are likely to be attenuated only when there is local magnetic disturbance related to enhanced ionization. The propagated influence of magnetic disturbance from other regions (as indicated by high $K_{p}$ ) should have little effect on local transmission of PP.

The diurnal variation of PP period may pos- 
sibly be explained in terms of attenuation. For a given electron density the ionosphere is more transparent to longer periods. Increasing the electron density moves the cutoff to shorter periods [Greifinger and Greifinger, 1965]. From this point of view the shortest-period PP activity would be just before sunrise. The observed period should then increase throughout the day to a maximum sometime in the afternoon.

At present there is no adequate experimental justification for the attenuation hypothesis suggested above. In fact, Campbell and Stiltner [1965] have found no correlation between the occurrence of PP activity and any normally measured ionospheric parameter. Nevertheless, there is still good reason to expect attenuation of PP activity in the ionosphere. Attenuation of Pc 1 band micropulsations is strongly influeneed by neutral particle-positive ion collisions in the $E$ layer. Ionospheric parameters are normally measured at much higher frequencies where the ionosphere may be treated as a lossy electron gas and where ion neutral particle collisions are of little importance. Thus the observational fact reported by Campbell and Stiltner that there is no correlation between PP activity and normally measured ionospheric parameters can perhaps be explained on this basis.

The preceding interpretation in terms of attenuation is only a tentative suggestion. It is almost certain that equal or greater control of PP characteristics arises as the result of the properties of the amplification mechanism. A theoretical analysis of this possibility is now being carried out.

Acknowledgments. This work was supported by the National Science Foundation under grant GP-1775, the Office of Naval Research of the United States Navy under contract 222 (89), and the National Aeronautics and Space Administration under grant 243-62.

\section{ReFERENCES}

Akasofu, S. I., A source of the energy for geomagnetic storms and auroras, Planetary Space Sci., 12, 801-833, 1964.

Anderson, K. A., and D. W. Milton, Balloon observations of $\mathrm{X}$ rays in the auroral zone, 3 ,
High time resolution studies, J. Geophys. Res., 69(21), 4457-4479, 1964.

Campbell, W. H., A study of geomagnetic effects associated with auroral zone electron precipitation observed by balloons, J. Geomag. Geoelec., $16(1), 41-61,1964$.

Campbell, W. H., and E. C. Stiltner, Some characteristics of geomagnetic pulsations at frequencies near $1 \mathrm{c} / \mathrm{s}$, Radio Sci., 69D(8), 1117-1132, 1964.

Cornwall, J. M., Cyclotron instabilities and electromagnetic emission in the ultra low frequency and very low frequency ranges, $J$. Geophys. Res., $70(1), 61-69,1965$.

Greifinger, D., and P. Greifinger, Transmission of micropulsations through the lower ionosphere, J. Geophys. Res., 70(9), 2217-2231, 1965.

Heacock, R. R., Auroral-zone telluric current micropulsations, $T<20$ seconds, $J$. Geophys. Res., 68(7), 1871-1884, 1963.

Heacock, R. R., and V. P. Hessler, Pearl-type micropulsations associated with magnetic storm sudden commencements, J. Geophys. Res., $70(5)$, 1103-1111, 1965.

Hessler, V. P., editor, High Latitude Geophysical Data, January-December 1964, Geophysical Institute, University of Alaska, Reports VAG-C(35-38), 1964.

Jacobs, J. A., and E. J. Jolley, Geomagnetic micropulsations with periods 0.3-3 seconds (pearls), Nature, 194, 641-643, 1962.

Pope, J. H., An explanation for the apparent polarization of some geomagnetic micropulsations (pearls), J. Geophys. Res., 69(3), 399-405, 1964.

Romana, A., and J. W. Cardus, S.J., Geometric rapid variations during IGY and IGC, J. Phys. Soc. Japan, 17, Suppl. A-11, 1962.

Saito, T., Mechanisms of geomagnetic continuous pulsations and physical states of the exosphere, J. Geomag. Geoelec., 16(2), 115-151, 1964.

Tepley, L. R., and R. C. Wentworth, Hydromagnetic emissions, $\mathrm{X}$-ray bursts, and electron bunches, 1, Experimental results, J. Geophys. Res., 67(9), 3317-3333, 1962.

Troitskaya, V. A., The microstructure of the magnetic storms in respect of pulsations for the first eight months of the IGY, Ann. IGY, 11, 62-68, 1961.

Wentworth, R. C., Sub ELF geomagnetic fluctuations, vol. 2, Slatistical Studies of Hydromagnetic Emissions, Final Report ( $A F 19$ (628)-46\%), Lockheed Missiles and Space Company, December 1963.

(Manuscript received July 19, 1965 ; revised August 17, 1965.) 